\title{
Articles
}

\section{Change and Conflict: Introduction of the Communicative Approach in China}

Janice Penner

Chinese resistance to the Communicative Language Teaching approach is often dismissed as the classic traditional versus modern approach debate. "The Chinese will soon change." However, because this is an example of cross-cultural exportation of educational innovations, there are many conflicts that must be resolved. This article examines how the beliefs, pedagogy, and structures that have developed in the Chinese English language classroom culture restrict pedagogical change advocated by foreign and Chinese change agents. The issues raised serve to acquaint the reader with some of the complexities of pedagogical change. The issues are also of significance to educators who are considering teaching in an EFL context.

China's modernization program and increased foreign contact have necessitated the expansion of English language training. At the request of the Chinese government and increasingly through foreign initiatives, foreigners have been acting as curriculum consultants and developers, researchers, English teachers, and teacher trainers at both tertiary and secondary levels. After 1979 the Ministry of Education, now the State Education Commission (SEC), launched numerous English as a Foreign Language (EFL) teacher training projects. For example, the Advanced Teacher Training Courses (ATTCs) focused on the teachers practicing at the college level (Oatey, 1990a, $1990 \mathrm{~b})$. Ambitious plans were also made to train or retrain all secondary EFL teachers (Wang, 1986).

China serves as an example of the problems inherent in the direct export of educational methodology across cultures. More specifically, this article outlines the conflicts that foreign and Chinese educators experienced when pedagogical change, intrinsic to implementing the Communicative Language Teaching (CLT) approach, was first introduced in EFL teacher training programs and EFL classes in China. Examples are drawn from teacher training and EFL classrooms because it was commonly assumed that the innovation presented to the Chinese English teachers would manifest itself in the teacher's own classroom. 


\section{Change}

In the process of educational reform, it is often assumed that change is natural and inevitable, yet for teachers, "learning a new skill and entertaining new conceptions create doubts and feelings of awkwardness or incompetence" (Fullan, 1991, p. 46). I believe the impact of change on the principal players, in this case Chinese teachers and students, has not been adequately addressed. A leading Canadian education sociologist explains that the "neglect of the phenomenology of change-that is, how people actually experience change as distinct from how it might have been intended-is at the heart of the spectacular lack of success of most social reforms" (Fullan, 1991, p. 4). Analyzing the type of change is also imperative.

First-order changes, according to Cuban (1988), "try to make what already exists more efficient and more effective, without disturbing the basic organizational features" (p. 342). Some examples of first-order changes in the Chinese context include revisions of EFL textbooks, raising salaries, and changes in resource allocation. Second-order changes, on the other hand, "seek to alter the fundamental ways in which organizations are put together.... introduce new goals, structure, and roles that transform familiar ways of doing things into new ways of solving persistent problems" (p. 342). In large part, change advocates were seeking second-order change in EFL in China after 1979.

\section{Teacher Training}

EFL teacher training programs were mainly staffed by foreigners who anticipated conducting programs that incorporated methodology, linguistics, classroom observation, materials testing, and development. "They assumed (subconsciously or otherwise) ... that the Chinese would want to learn about current Western ideas on the teaching of languages" (Oatey, 1984, p. 358). Many were surprised with the resistance and lack of apparent change in teaching practice.

One reason for resistance was their differing expectations of teacher training. Many Chinese teachers wanted teacher training to be language improvement and considered methods to be secondary. Liu (1988) explains that "the study of methods for teaching English to speakers of other languages has never been highly valued, even in teacher training programs" (p. 71). In part methodology had a lower profile because it was considered a noncontent subject, and therefore it could not be tested in a more traditional manner. This unmeasurable aspect gave it less prestige and made it "professionally unattractive" (Sunderland, 1990, p. 230).

Views on what constitutes effective teaching also influenced the impact methodology training had. Many Chinese believed, "if their teachers 'know' more English, they will teach better" (Maley, 1985, p. 103). For training, then, the foreign teacher trainers were focused on the technically oriented how 
(methods), whereas the Chinese were focused on the what (knowledge of the language). Even the superiors of the ATTC graduates, on the whole, just wanted the teachers "to do the same job better through their own language improvement, without any particular change in their methodology" (Sunderland, 1990, p. 240). It is no surprise, then, that because the expectations of the foreign teacher trainers differed from the felt needs and expectations for language improvement of the Chinese teachers, the result was resistance.

Nevertheless, the government continued to promote change. For example, the College English Syllabus (1985) was approved and promulgated. Yang (1990) states it "emphasizes communicative competence ... is neither purely grammatical nor purely functional. It is eclectic" (pp. 157-158). Yang admits "the teachers need retraining before they may accept and decide to implement the new syllabus" (p. 162). In a 1990 report (Adamson, 1991) the SEC criticized the focus on linguistic rather than pedagogical development in methodology courses. Officially, then, there was a desire to shift from the what to the how of teaching in teacher training programs.

In the ELT teacher training programs Chinese and foreign educators were divided on whether the concentration should be on methodology training (Yu, 1984; Wang, 1986), language proficiency (Grabe \& Mahon, 1981; Burnaby \& Sun, 1989), or properly designed materials (Patrie \& Daum, 1980; Wu, 1983b; Cowan, Light, Mathews, \& Tucker, 1979). Even though there was enthusiasm for improvement in EFL, acceptance of modern ideas and quick adoption of new materials and methodology, "progress in all these aspects has been slow, particularly the development of a consensus as to what should be the ideal methodology, or at least the basic principles guiding the solutions of problems" (Dzau, 1990, p. 4). One reason for this slow progress lies in the nature of the two teaching approaches.

\section{The Two Approaches}

Throughout this article the terms the Chinese traditional approach and Communicative Language Teaching (CLT) approach are used in a general sense. Other terms that have been used to describe the two positions include traditional/modern, structural/communicative, and transmission/interpretation (Young \& Lee, 1987). In this analysis the two approaches are contrasted; however, this juxtaposition is not meant to foster stereotypical images or overgeneralizations, nor to show that one approach is better than the other. It would be wrong to claim that all Chinese and all Western teachers conform to the norms described here.

Both the Chinese traditional and the foreign communication-based approaches are eclectic. The Chinese traditional approach has

focused on academic study of grammar, literature, and in-depth analysis of literary texts, following traditional Chinese scholarly practice and 
American and Soviet influences on the structure and content of Chinese education ... various traditional Chinese educational strategies, which were inclined toward memorization, discussion, and grammar translation, have combined with Western influences on Chinese education in this century, such as missionary use of total immersion in the foreign language, American focus on the study of literature, phonetic study of English pronunciation, the Direct Method, Soviet traditions of intensive and extensive reading (from French origins), and the audiolingual method. The result of these influences have tended toward grammar translation, intensive reading and the study of literature. (Burnaby \& Sun, 1989, p. 222)

The more communicative approach is also an evolution of various methods and approaches that reflect more recent applied linguistic research and educational theory. Ting (1987) has highlighted their common denominators. "They all emphasize (i) independent, inquisitive work by the learner, (ii) target language communication in the course of learning, (iii) the development of skills in understanding, speaking, reading and writing as the goal of teaching" (p. 55).

The focus in the Chinese approach on teacher, textbook, and grammar is in almost direct contrast to the CLT focus on learner, practice, and skill development. Both of these approaches evolved to serve specific historical conditions and reflect applied linguistic and learning theory claims.

A major issue is that the CLT approach, which was mainly established through practice and research in an ESL context, was being promoted in an EFL context. Space here does not permit a discussion on the differences between ESL and EFL settings. Obviously the teachers and students in China did not have the same opportunities to reinforce their classroom learning as their ESL counterparts. Sampson (1984) challenges educators to develop a conceptual framework for adopting a method developed in one context to another.

\section{Classroom Culture}

Because "a program plan or a curriculum is more than a list of teaching strategies and materials, but is also a set of assumptions and implied roles which do have implications for the teacher" (Werner, 1988, p. 88) it is necessary to look at the conflicts that arose when educators attempted to implement the CLT approach into a traditional Chinese language classroom. The conflicts can be classified using a culture of the classroom framework. Classroom culture is manifested through at least three basic elements: beliefs, pedagogy, and structure (Werner, 1991). Beliefs are based on shared values and expectations of all the participants, including the role of the teacher, the role of the students, and beliefs about language learning. Pedagogy involves what is done in the classroom: methods, use of materials, objectives, and 
evaluation. Structure includes the organization of time, space, people, and resources. The three elements are not mutually exclusive. For example, if it is expected that the teachers' role is to transmit knowledge (belief), then the methods in the class will be teacher-centered (pedagogy). With this teaching role, the number of students (structure) can range from 10 to 70 without challenging or affecting the beliefs or pedagogy.

\section{Belief: Language Learning}

The essential characteristics of the Chinese view of language learning are memorization, repetition, habit formation, and the quantitative accumulation of knowledge (Yu, 1984; Scovel J., 1983; Wu, 1983a). These beliefs and strategies reflect the experiences of older Chinese people who learned classical Chinese. In essence, repetition, memorization, and habit formation are conditions for the mastery of form, which eventually leads to the understanding and creative use of the language. When people studied the Chinese classics, "they were not expected to understand what they memorized but later, when they were older, they all 'suddenly understood what they memorized"" (Dzau, 1990, p. 53). The following Chinese saying captures the relationship between learning and creative use: "When one can memorize 300 Tang poems, he is sure to be able to compose poems of his own even though he is not a poet." Because language is viewed as knowledge (an end) and learning is mastery/acquisition of those data, then errors are viewed as inadequate study, inadequate memorization, or bad habits (Allen \& Spada, 1982; Zhang, 1982).

The CLT approach views learning as a skill development rather than a knowledge receiving process. It is believed that students learn through using and experimenting with English, which is viewed as a means for communication. Errors are tolerated because they are viewed as indicators of development. In other words, the CLT approach assumes that English is "knowledge how to," that is, skills, proficiency, and functions, whereas the traditional approach focuses on the "knowledge of" grammar, lexicon, and rules.

If the CLT approach is implemented in a previously traditional classroom, the Chinese teachers and students must make a conceptual shift as to what English means and also how to study and learn it. Because these principles of learning permeate the entire Chinese education system, is it reasonable and even ethical to expect teachers and students to change their teaching/learning beliefs for only one subject area?

\section{Belief: Role of the Teacher}

There were at least four broadly defined groups of English teachers involved in teacher retraining programs in China:

the Russian "retreads" (teachers of Russian hastily retrained, or simply redeployed, as English teachers), pre-1966 English teachers (trained 
when audio-lingualism was prevalent) and post-1978 English teachers, with some exposure to the Communicative Approach. (Non-English teachers, conscripted from other subjects make up a fourth group, which is probably the largest). (Adamson, 1991, p. 4)

No matter which of these four groups teachers may be classified in, their role is essentially authoritative.

In the Chinese approach, the primary role of the teacher, whose authority comes from holding all the knowledge, is to transmit that knowledge to the students. Influenced by the Confucian tradition, "the language teacher has the sole authority in the classroom and therefore should not be questioned, interrupted or challenged" (Ting, 1987, p. 53). If the teacher errs, it is assumed that the teacher has not prepared adequately and therefore has not fulfilled his or her duty (Allen \& Spada, 1982). As a result, "this obligation to provide instant and specific answers has led to a focus on the end product, and general underestimation of that process of learning where the effort involved in finding out, processing, or recalling information leads to greater memorability" (Byron \& Macmillan, 1990, p. 195).

On the other hand, in a more communicative approach the teacher takes on a "helper" rather than "knower" role (Oatey, 1984). Because the focus is on the students' development, "the teacher's job is only to provide the conditions for this process, set it going, observe it, try to understand it, give guidance, help it along, analyze and evaluate it" (Li, 1984, p. 9). Only? This helper role implies a different set of skills than a knower role. Change agents must recognize that it takes time and experience for teachers to understand and effectively carry out this new role.

This radical change was difficult for the Chinese teachers to accept for several reasons. Many teachers were teaching to the limits of their knowledge of English, so it was very threatening to use methods that allowed for unpredictability, such as student questions. While trying to use the new methods, some teachers expressed that they felt uprooted and guilty because they were not doing their duty ( $\mathrm{Li}, 1984)$. These were significant concerns as the teachers were challenged to change their beliefs and values about their identity. Young and Lee (1987) conclude that Falvey's (1983) study about implementing fluency activities with native Chinese speaking English teachers in Hong Kong clearly shows "innovation is not likely to succeed through teacher retraining programmes unless such programmes are able to bring about a corresponding shift in teachers' attitudes towards the nature of language learning and towards their own role in that process" (p. 90).

One could argue that foreign language teachers in other countries once taught in the traditional way and have changed their roles, so teachers are able to change their teaching behavior and roles. This is true; however, the Chinese teachers had no context in which to place this new approach. "They've been isolated from learning theory and know little of the develop- 
ments in thought that have spawned these changes in classroom approach" (Grabe \& Mahon, 1981, p. 208). The implication here is that additional knowledge of learning theory might effect a change in teachers' attitudes and teaching practice. However, more than a decade later, Campbell and Zhao (1993) tell us

But even though the professional literature in China reveals a clear understanding of the communicative approach, the importance of viewing communication as the organizing principle of foreign language instruction continues to exist in the professional literature to a far greater extent than in actual practice. (p. 4)

This is why Patrie and Daum (1980) proposed that pedagogical change agents "should contribute to evolution, not revolution, in EFL methodology in China" (p. 394).

From experience $I$ have found that Chinese students accepted the different roles and methods from foreign teachers more easily than from Chinese teachers. It appeared that in the classroom, Chinese should act Chinese and foreigners should act foreign. In an example of implementing a different methodology, Gao (1992) reported on her students' reaction to her using the Rassias Method. She points out "those students who rejected the new techniques tend to believe that cultural identity ('we are Chinese') and cultural context ('we are now in China') determine the inappropriateness of the teacher behaviors" (p. 38). It appears, then, that the resistance was not only a concern with roles in the classroom, but also roles in the culture as a whole.

\section{Belief: Role of the Student}

The CLT approach assumes the student is willing to be an active participant, whereas the traditional approach allows for seemingly passive receiver behavior. With CLT much more responsibility is given to the student for his or her own learning, and this reflects a fairly recent shift in North American education. Chinese institutions and teachers, however, tend to assume almost full responsibility for the learning that occurs. Furthermore, the CLT students must be able to actively and appropriately use English because often progress is determined by oral participation. In the traditional approach, the students are required to be able to memorize English and answer discrete point grammatical questions, as creative use is believed to come later. Relationships are also clearly defined. "The Chinese student's traditional attitude towards his teacher is one of respect, obedience, and reliance, a reliance that is often dependence" (Dzau, 1990, p. 83).

If CLT behaviors are required, the students will in turn need to redefine some of these attitudes. For example, behavior attached to the concept of respect and saving face prevents students from questioning their teachers. 
Questions imply that teachers have failed in their duty to impart knowledge clearly. Because asking questions in the CLT classroom is encouraged, the students will not only have to redefine their concept of respect, but also participate differently in their learning experience.

In a shift from a traditional to a CLT classroom, students also need to learn different learning strategies that are more conducive to the activities. The study skills course outlined by Sunderland, Zhao, Huang, and Barr (1988) proved to be an excellent approach for teachers and students to realize "how to learn what should be learned" (p. 35).

\section{Pedagogy: Evaluation and Objectives}

Both the Chinese and the CLT approaches aim to meet the needs of the students. For many teachers in the Chinese context, the aim is to provide the grammatical and vocabulary knowledge so the students can successfully pass the many exams they must take in their academic career. English is one of the six components of the national university entrance exam. (Stringent grammatical analysis exams were also in place for teachers entering some foreign funded inservice teacher training programs.)

These examination and other curriculum decisions are not in the teacher's domain. The SEC clearly defines the aims, objectives, and linguistic criteria for each level of schooling; prescribes or recommends the textbooks; determines the time allocation and teaching methodology (in secondary schools, Tang, 1983); and tightly controls the secondary and university entrance exams (Scovel T., 1983). Because of the restrictive relationship between the curriculum and examination criteria, teachers believed that their grammar translation approach successfully prepared students for the exams. Students also felt this contextual constraint and thus pressured their teachers to teach for the examinations (Burnaby \& Sun, 1989).

Very little research has been done to see how students learning with the CLT approach actually do on the university entrance exams. One example of method effectiveness research was done at Nanjing University. Their skillbased approach was an attempt to break away from the predominant audiolingual Intensive Reading (IR) freshman course. They found "the experiment class performed better in all the tests on the four skills except in the grammar section" (Yue, 1990, p. 149). These findings are not surprising because they did not attach any importance to grammar and translation in their training course.

The CLT approach aims to help students gain communicative competence. Chinese teachers had experience evaluating grammatical competence; however, because of their own limitations, they felt they could not properly evaluate the sociolinguistic, discourse, and strategic elements inherent in the CLT approach. The CLT approach "requires holistic evaluation by people with native-speaker or near native-speaker competence" (Burnaby 
\& Sun, 1989, p. 235). Acceptable qualitative evaluation instruments have not yet been designed. Furthermore, even in the North American context, CLT language testing is fraught with controversy, and "many a curricular innovation have been undone by failure to make corresponding changes in evaluation" (Savignon, 1991, p. 266). Campbell and Zhao (1993) suggest that if the examination were changed "to better measure communicative proficiency ... The very system that now subverts effective language training has the potential to become its progenitor" (p. 6).

The Chinese teachers interviewed by Burnaby and Sun (1989) felt the Chinese approach is suitable for examination and translation preparation, whereas the communicative approach is only useful for preparation of students going abroad. Chen (1988) also argues that the greatest demand in China is for foreign language teachers and translators of science and technology. Because these groups require intense grammatical training, "the grammar translation method seems to have a justified place in the foreign language classroom in China while the communicative approach is unsuitable as the main approach in foreign language teaching in China" (p. 74). The problem, then, with meeting the objectives of ELT in China was the existence of two vastly different learner needs: discrete point examination preparation and real-life communication skills. Because job placements were usually not assigned until after university graduation, neither students nor teachers knew who would need communicative competence. This, in combination with the exam system, contributed to the continuation of the traditional approach.

\section{Pedagogy: Methods and Use of Materials}

English course syllabi vary across institutions, but generally the components are similar. Intensive Reading (IR) is the main first-year course, and Extensive Reading, Oral English, English Grammar, Listening, and Composition and/or Translation are considered supplementary (Dzau, 1990).

The use of the textbook, classroom procedures, and preparation of lessons has been significantly influenced by Confucian principles and Russian educational practice (Shen, 1984; Scovel J., 1983; Price, 1987; Porter, 1990). It appears that Russian pedagogical practice reinforced the Chinese philosophical principles, making the adoption or assimilation of grammar translation quite smooth and thorough. Yu (1984), Shen (1984), and J. Scovel (1983) posit that language teaching reforms have been inhibited because of the previous adoption of the Russian 5-Step teaching methodology. According to Kairov, the 5-step teaching method consists of: (a) reviewing the old material; (b) orienting the new material; (c) explaining the new material; (d) consolidating the newly learned material; and (e) giving assignments ( $\mathrm{Yu}$, 1984). 
Textbooks, held in the highest place of authority, were used for IR. Literature texts, which have replaced the Four Books and Five Classics (attributed to Confucius), were used for grammatical and syntax analysis. Even though IR was an ad hoc examination of the language and there were many arguments against its dominance (Yue, 1990), the teachers believed the students learned the analytical skills that were needed for passing exams, reading technical articles, and translating documents (Burnaby \& Sun, 1989).

Another aspect of Soviet influence was the collective preparation of materials and exercises. "Most teachers spend many hours a week meeting with their colleagues to decide on common materials and methods, uniform explanation of content, points of usage and meanings of words" (Dzau, 1990, p. 77). These activities provided security for the teachers ( $Y u, 1984)$, but did not foster individual confidence and increased language competence.

Near native-speaker language proficiency and confidence are essential for teachers using the CLT approach. Teachers are encouraged to utilize authentic English language materials (radio broadcasts, newspaper articles, real-life dialogues, etc.) rather than a prescribed textbook. Some of the activities that encourage language use and learner autonomy involve group discussions, role plays, creative writing, peer correction of errors, extensive reading skills (skimming, scanning, etc.), guessing vocabulary meanings from context, playing games, and singing songs. All these activities are based on assumptions about learning. The Chinese teachers, however, were not convinced of the value of these authentic, interesting, and student-centered activities. Many Chinese teachers and students argued that these less directive activities were a waste of time. Furthermore, Allen and Cooke (1981) wrote that some claimed "the Chinese [have] a much longer attention span, that it [is] difficult to bore them, and that they would prefer not shifting from activity to activity" (p. 26).

The Chinese teachers had many other reservations about changing their teaching methods. These included (perceived) inadequate language proficiency and target language cultural knowledge, inexperience with creating materials and exercises, lack of resources, and criticism from peers and superiors for deviating from the government approved curriculum (Burnaby \& Sun, 1989). Sampson (1984) reports that the Chinese teachers

complained that there are just too many new and different methods for teaching English and no criteria for choosing among them, except perhaps one's emotional proclivity towards one or the other. And in a country such as China with an intellectual tradition stemming from ancient times, emotional proclivity is not seen as an appropriate way of dealing with major educational decisions. (p. 21) 
Making these decisions assumes the teachers have knowledge of all the various alternatives. Is it assumed that knowledge of the applicable method will ensure its implementation?

\section{Structure: People and Space}

The CLT approach has implications for the structures in the language classroom. Most North American ESL classes have a maximum of 20 students; thus values inherent in the CLT approach, such as attention to individual students, are more manageable. In contrast, a Chinese teacher with 50 or more students in an EFL class is understandably overwhelmed with the duty of providing individual attention and allowing for individual participation. To promote student interaction, small-group activities were recommended by communicative approach advocates; however, Chinese teachers viewed this as a threat to their control and status (Allen \& Spada, 1982). They felt they would not be able to fulfill their duty by correcting student errors. Moreover, school principals and colleagues in neighboring classrooms have been known to complain of the noise, implying the teacher's lack of control. Physical limitations also existed; for example, Chinese teachers claimed it was difficult to arrange the students in groups of four when the desks were bolted to the floor in long rows facing the teacher.

\section{Structure: Time}

The CLT approach also has implications for the teacher's use of time outside and inside the classroom. Because of the severe shortage of English teachers, they were already working more hours than their counterparts in other departments. The shortage was the most severe in the outlying areas. For example, in Jiangxi province, $\mathrm{Hu}$ (1990) reports that the ratio of EFL middle school teachers to students is 1:340. She admits this "means either the teacher is overworked or English is not offered" (p. 60). The shortage was also evident in universities in major cities. I spoke to a university English teacher who taught 24 hours a week (a total of 200 students), whereas her husband, a math teacher, only taught four hours a week. She was concerned with the extra time and energy required to create a variety of authentic student centered materials. Even "Freer Practice," Step 5 of the IR course was neglected in many universities because of the lack of time (Dzau, 1990).

Furthermore, teachers believed that learning in the traditional Chinese way (memorization, etc.) was a more efficient use of time than learning with the indirect communicative approach. Accordingly, teachers feared that using the communicative techniques for three hours a week with a large class was not sufficient time to cover the prescribed curriculum/examination content effectively (Burnaby \& Sun, 1989). 


\section{Structure: Resources}

The quality of instruction and the distribution of resources were dependent on the school's position in the national hierarchy. For example, the hierarchical and elitist system of schools determined how equipment was distributed. At the tertiary level, national institutions and foreign language institutes were favored over local provincial or municipal ones. The secondary schools were ranked in descending order from municipal key schools to technical and specialized secondary and vocational institutions, to regular academic schools on down to the rural minban schools (Ross, 1991). Some schools did not have the audiovisual equipment such as overhead projectors, video-recorders and players, and language labs that are used to support the communicative techniques. Access to the photocopier for making class sets of teacher-created exercises was usually unavailable. Even mimeographed work might have required an application for funds. "Intensive instruction with the best qualified teachers [and up-to-date audiovisual equipment] is reserved for that tiny minority who will be expected to put the language skills to use in a lifetime career" (Light, 1978, pp. 96-97; Ross, 1987), whereas the textbook was the sole source of English for most rural schools (Wang, 1986; Kristoff, 1991). Because all students must take the English component on the university entrance exam, we see that this unequal distribution of resources helped to maintain the elite access to university education.

Changes in pedagogy naturally place demands on corresponding structural concerns. It is unlikely that foreign teacher trainers could influence these factors, yet they must recognize their existence and empower the teachers to discern possibilities of adapting the CLT approach to work within these externally established boundaries. Furthermore, pedagogical change should address the conflicts within the whole cultural context rather than one factor in isolation.

\section{Pedagogical Synthesis: A Chinese Way}

Because of the discrepancies in educational theory, roles, expectations, methods, material use, and structural concerns, Chinese and some foreign educators advocate that a new "Chinese way" be developed ( $\mathrm{Yu}, 1984$; Wang, 1986; Shen, 1984; Burnaby \& Sun, 1989). Young and Lee (1987) suggest that,

given the apparent stability of Chinese teachers' attitudes, and the radically different attitudinal norms of Chinese and Anglo teachers, the approach of designing a cultural appropriate curriculum may in the long run be more effective in promoting better EFL teaching and learning than attempts at attitude change. (p. 97)

Similarly, some educators agree that "the English language is foreign, but the teaching of it should be Chinese" (Liu, 1988, p. 76). 
Developing a Chinese Way is consistent with the mutual adaptation model of implementing change. Fullan (1991) explains there are at least two possibilities for implementing change.

The fidelity approach ... is based on the assumption that an already developed innovation exists and the task is to get individuals and groups of individuals to implement it faithfully in practice.... The mutual adaptation or evolutionary perspective stresses that change often is (and should be) a result of adaptations and decisions made by users as they work with the particular new policies and programs. (p. 38)

A Chinese Way is also congruous with how China has historically managed to adapt rather than adopt. Two historic slogans express this: "Let the past serve the present; make foreign things serve China" (Mao Zedong: Gu wei jin yong: Yang wei zhong yong) and "Chinese essence, Western practice" (zhongti xiyong). Hayhoe (1986), a Canadian expert on China states

Something in the strength of the Chinese culture-also the fundamental independence and dynamic awareness of the Chinese psyche-has made it possible for these massive transfers of knowledge and technology to be turned to different ends than those intended by the donor countries. (p. 539)

In 1989 the SEC proposed "we should make further researches into all the pedagogic schools [i.e., grammar translation, audiolingualism, the "communicative approach," etc.] rejecting the dross and assimilating the essence, and make them serve us according to our national conditions" (Adamson, 1991, p. 5). The question is, what is defined as "the dross?" Who will make those decisions about a new pedagogy: will it be the party members, SEC administrators, teacher trainers, or teachers? Foreigners or Chinese? The need for research on the process of pedagogical change and implementation in China is clear.

An increasing number of Chinese educators have been exposed to SLA theories, methodological approaches, and so on through training courses in China and through graduate studies abroad. This provides the opportunity for significant research on how these classroom culture conflicts can be resolved.

The greatest gap now confronting foreign language educators in China appears to be the absence of applied research to inform program decision-making... The result is that there is virtually no empirical data now available to assess which innovations have been effective or ineffective, to guide future developments with confidence, or even to support theorizing which might justify current practices. (Cumming, 1987, p. 216) 
Through more research and experience, Chinese educators will be able to determine which aspects of the communicative approach can be adapted or adopted to suit their teaching and learning culture.

\section{Conclusion}

The second-order changes that are apparent with implementing the CLT approach are challenging, but a deeper understanding of the conflicts will provide insight into resolution. Broad-scale implementation will also prove difficult because of China's immense population and size. Nevertheless, as Chinese and foreign educators continue to develop theories and methods, the changing language needs of China will be met.

Although this article specifically addresses a pedagogical change process in China, the issues are relevant in "traditional" classrooms in other countries. Some specific strategies that foreign experts can utilize when teaching English abroad are highlighted below.

Learning as much about the educational culture before going can ease teachers' classroom culture shock. Along with talking to people from the host culture about their classroom experiences, teachers can learn about the educational context from informative comparative education articles. Inviting learners to share their reactions to the different approaches can help the learners understand their own classroom culture shock. As the learners articulate their previous learning experiences, preferences, and analyses, they will participate more fully in the change process. If they are unable to express themselves in English, I suggest that they be encouraged to speak in their mother tongue. In addition, sharing the process of change with experts in the host culture is necessary if lasting second-order change is expected. The most common concern host country EFL experts and teachers have expressed to me is that foreign experts do not respect their experience and insight. Taking time to reflect on the teaching and learning experience will provide data for regular pedagogical discussions with host country colleagues. Explaining the teaching and learning assumptions underlying teaching activities will contribute further to the learners' understanding of their learning process. Often learners resist activities, such as singing songs or playing games, because they do not recognize their pedagogical value. Nurturing a relationship based on reciprocal rather than unidirectional expertise will prove to be most effective in effecting pedagogical change. In conclusion, the most important element in this pedagogical change debate is that all the participants clarify their own cultural learning and teaching assumptions, as understanding another culture can really only occur when people understand their own. 


\section{Note}

An earlier version of this paper was presented at the Second International Conference on Teacher Education in Second Language Teaching, City Polytechnic of Hong Kong, March 24, 1993.

\section{Acknowledgements}

I appreciate the questions, insights, and suggestions of the TCJ editors and reviewers. I also gratefully acknowledge my Chinese EFL colleagues who shared their concerns and experiences with me and encouraged me to write this paper.

\section{The Author}

Janice Penner is a master's student of curriculum and instruction at the University of British Columbia. She has taught in ESOL and teacher training programs in Beijing, Taipei, Edmonton, and Vancouver. Her research interests include the use of mother tongue in the language classroom and undergraduate student learning experiences with international teaching assistants.

\section{References}

Adamson, B. (1991, April). Future directions in junior secondary English language teacher development in the People's Republic of China. Paper presented at the International Conference on Teacher Education in Second Language Teaching, Hong Kong.

Allen, W., \& Cooke, D. (1981). Bridging the gulf: Materials development in China. TESL TALK, 13(2), 23-32.

Allen, W., \& Spada, N. (1982). A materials writing project in China. Language Learning and Communication, 1(2), 187-195.

Burnaby, B., \& Sun, Y. (1989). Chinese teachers' views of western language teaching: Context informs paradigms. TESOL Quarterly, 23(2), 219-238.

Byron, S., \& Macmillan, M. (1990). The role of the language teacher in distance education. In Y.F. Dzau (Ed.), English in China (pp.193-202). Hong Kong: API Press.

Campbell, K.P., \& Zhao, Y. (1993). The dilemma of English language instruction in the People's Republic of China. TESOL Journal, 2(4), 4-6.

Chen, S.Q. (1988). A challenge to the exclusive adoption of the communicative approach in China. Guidelines, 10(1), 67-75.

Cowan, J.R., Light, R.L., Mathews, E., \& Tucker, R. (1979). English teaching in China: A recent survey. TESOL Quarterly, 13(4), 465-482.

Cuban, L. (1988, January). A fundamental puzzle of school reform. Phi Delta Kappan, 69, 341-344.

Cumming, A. (1987). Evaluations and developments of foreign language teaching in China. Canadian and International Education, 16(1), 211-220.

Dzau, Y.F. (Ed.). (1990). English in China. Hong Kong: API Press.

Fullan, M. (1991). The new meaning of educational change. New York: Teachers College Press.

Gao, Y. (1992, January). The appropriateness of nonverbal classroom behaviors. English Teaching Forum, 38-40.

Grabe, W., \& Mahon, D. (1981). Comments on methodology-oriented teacher training programs in China. TESOL Quarterly, 15(2), 207-209.

Hayhoe, R. (1986). Penetration or mutuality? China's educational cooperation with Europe, Japan, and North America. Comparative Educational Review, 30(4), 532-559.

Hu, Y.N. (1990). Teaching English in Chinese secondary schools. In Y.F. Dzau (Ed.), English in China (pp. 59-67). Hong Kong: API Press.

Kristoff, N.D. (1991, May 6). Chinese learn English and find it a mouthful. The New York Times. International Edition. 
Li, X. (1984). In defense of the communicative approach. English Language Teaching Journal, $38(1), 2-13$

Light, T. (1978). Foreign language teaching in the People's Republic of China. In C.H. Blatchford \& J. Schacter (Eds.), ON TESOL 78: EFL policies, programs, practices (pp. 90-97). Washington, DC: TESOL.

Liu, X. (1988). An analysis of factors that hinder TESOL innovations in China. TESL Reporter, 21(4), 70-77.

Maley, A. (1985). On chalk and cheese, babies and bathwater and squared circles: Can traditional and communicative approaches be reconciled? In P. Larson, E.L. Judd, \& D.S. Messerschmitt (Eds.), On TESOL'84, A brave new world for TESOL (pp. 159-169). Washington, DC: TESOL.

Maley, A. (1986). XANADU-“A miracle of rare device": The teaching of English in China. In J.M. Valdes (Ed.), Culture bound (pp. 102-111). Cambridge, UK: Cambridge University Press.

Oatey, H. (1984). Teacher training in the People's Republic of China: A case report. Language Learning and Communication, 3(3), 353-363.

Oatey, H. (1990a). Developments in the training of English teachers, 1979-1989. In F.Y. Dzau (Ed.), English in China (pp. 203-221). Hong Kong: API Press.

Oatey, H. (1990b). Teacher training in the PRC: Influence of sociocultural factors. In F.Y. Dzau (Ed.), English in China (pp. 250-261). Hong Kong: API Press.

Patrie, J., \& Daum, D. (1980). Comments on the role of foreign expertise in developing nations: A summation of the findings of an exchange of ESL specialists with the People's Republic of China. TESOL Quarterly, 14(3), 391-394.

Porter, E.A. (1990). Foreign teachers in China: Old problems for a new generation, 1979-1989. New York: Greenwood Press.

Price, R.F. (1987). Convergence or copying: China and the Soviet Union. In R. Hayhoe \& M. Bastid (Eds.), China's education and the industrialized world (pp. 158-193). Armonk, NY: Sharpe.

Ross, H. (1987). "Making foreign things serve China": A historical ethnography of a Chinese foreign language middle school. Unpublished manuscript, University of Michigan.

Ross, H. (1991). The "crisis" in Chinese secondary schooling. In I. Epstein (Ed.), Chinese education: Problems, policies and prospects (pp. 66-107). New York: Garland.

Sampson, G.P. (1984). Exporting language teaching methods from Canada to China. TESL Canada Journal, 1(1), 19-31.

Savignon, S.J. (1991). Communicative language teaching: State of the art. TESOL Quarterly, 25(2), 261-275.

Scovel, J. (1983). English teaching in China: A historical perspective. Language Learning and Communication, 2(1), 105-109.

Scovel, T. (1983). The impact of foreign experts, methodology and materials on English language study in China. Language Learning and Communication, 2(1), 83-91.

Shen, B. (1984). An investigation into some questions concerning the current teaching of foreign languages in institutions of higher education. Chinese Education: A Journal of Translations, 19(1), 117-125. [Original source: Dui muiqian gaoxiao waiyu jiaoxue zhong yi xie wenti de tantao. Gaojiao Zhanxian [Higher Education Front], 8, 29-31.]

Sunderland, J. (1990). "Doing what the Romans don't do": Advanced teacher training courses in China. In F.Y. Dzau (Ed.), English in China (pp. 222-149). Hong Kong: API Press.

Sunderland, J., Zhao, J, Huang, W., \& Barr, B. (1988). Starting with study skills: A two-week intensive study skills course prior to one year's in-service teacher training on an advanced teacher training course. ELT Newsletter, p. 16. Beijing: British Council.

Tang, L.X. (1983). TEFL in China: Methods and techniques. Shanghai: Shanghai Foreign Language Education Press. 
Ting, Y.R. (1987). Foreign language teaching in China: Problems and perspectives. Canadian and International Education, 1(1), 48-61.

Wang, K. (1986). Teaching English as a foreign language in China. TESL Canada Journal, 4(1), $153-160$.

Werner, W. (1988). Understanding school programs. Unpublished manuscript, University of British Columbia.

Werner, W. (1991). Lectures on educational change and innovation. University of British Columbia, September-November.

Wu, J.Y. (1983a). Eclecticism: A Chinese viewpoint. Language Learning and Communication, 2(3), 287-293.

Wu, J.Y. (1983b) QUCHANG BUDUAN-A Chinese view of foreign participation in teaching English in China. Language Learning and Communication, 2(1), 111-116.

Yang, H. (1990). The design of a new syllabus-A case report. In F.Y. Dzau (Ed.), English in China (pp.152-163). Hong Kong: API Press.

Young, R., \& Lee, S. (1987). EFL curriculum innovation and teacher's attitudes. In R. Lord \& H.N.L. Cheng (Eds.), Language education in Hong Kong. Hong Kong: Chinese University Press.

Yu, C.C. (1984). Cultural principles underlying English teaching in China. Language Learning and Communication, 3(1), 29-39.

Yue, M. (1990). A skill-based approach to freshman English. In F.Y. Dzau (Ed.), English in China (pp. 134-151). Hong Kong: API Press.

Zhang, Z.B. (1982). TEFL at the Shanghai Foreign Language Institute. Language Learning and Communication, 1(3), 289-293. 